
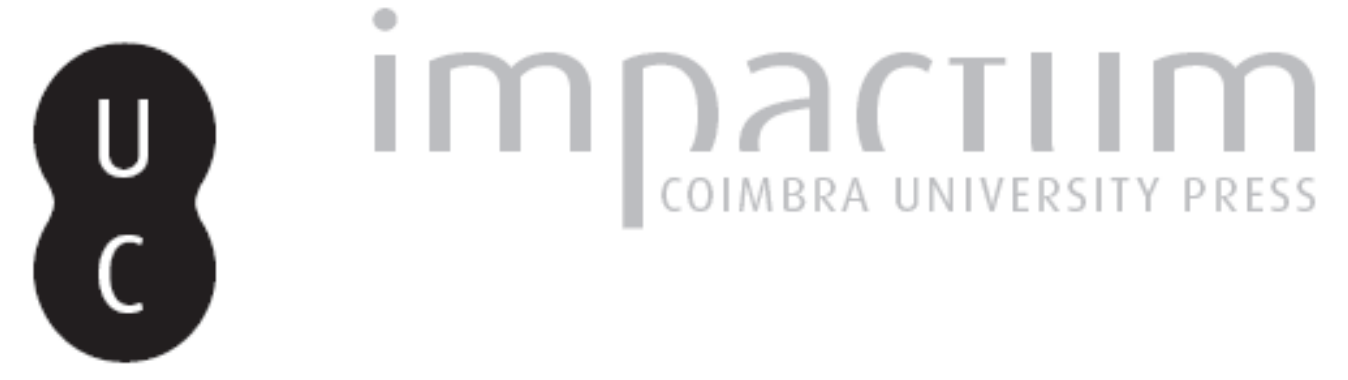

\title{
[Recensão a] Soares, Lucas - Enseñar filosofía o filosofía del enseñar: acerca de Platón y la política
}

\author{
Autor(es): Bieda, Esteban \\ Publicado por: Annablume Clássica; Imprensa da Universidade de Coimbra \\ URL \\ persistente: URI:http://hdl.handle.net/10316.2/24316 \\ DOI: $\quad$ DOI:http://dx.doi.org/10.14195/1984-249X_9_16 \\ Accessed : $\quad$ 26-Apr-2023 05:16:56
}

A navegação consulta e descarregamento dos títulos inseridos nas Bibliotecas Digitais UC Digitalis, UC Pombalina e UC Impactum, pressupõem a aceitação plena e sem reservas dos Termos e Condições de Uso destas Bibliotecas Digitais, disponíveis em https://digitalis.uc.pt/pt-pt/termos.

Conforme exposto nos referidos Termos e Condições de Uso, o descarregamento de títulos de acesso restrito requer uma licença válida de autorização devendo o utilizador aceder ao(s) documento(s) a partir de um endereço de IP da instituição detentora da supramencionada licença.

Ao utilizador é apenas permitido o descarregamento para uso pessoal, pelo que o emprego do(s) título(s) descarregado(s) para outro fim, designadamente comercial, carece de autorização do respetivo autor ou editor da obra.

Na medida em que todas as obras da UC Digitalis se encontram protegidas pelo Código do Direito de Autor e Direitos Conexos e demais legislação aplicável, toda a cópia, parcial ou total, deste documento, nos casos em que é legalmente admitida, deverá conter ou fazer-se acompanhar por este aviso.

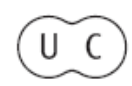




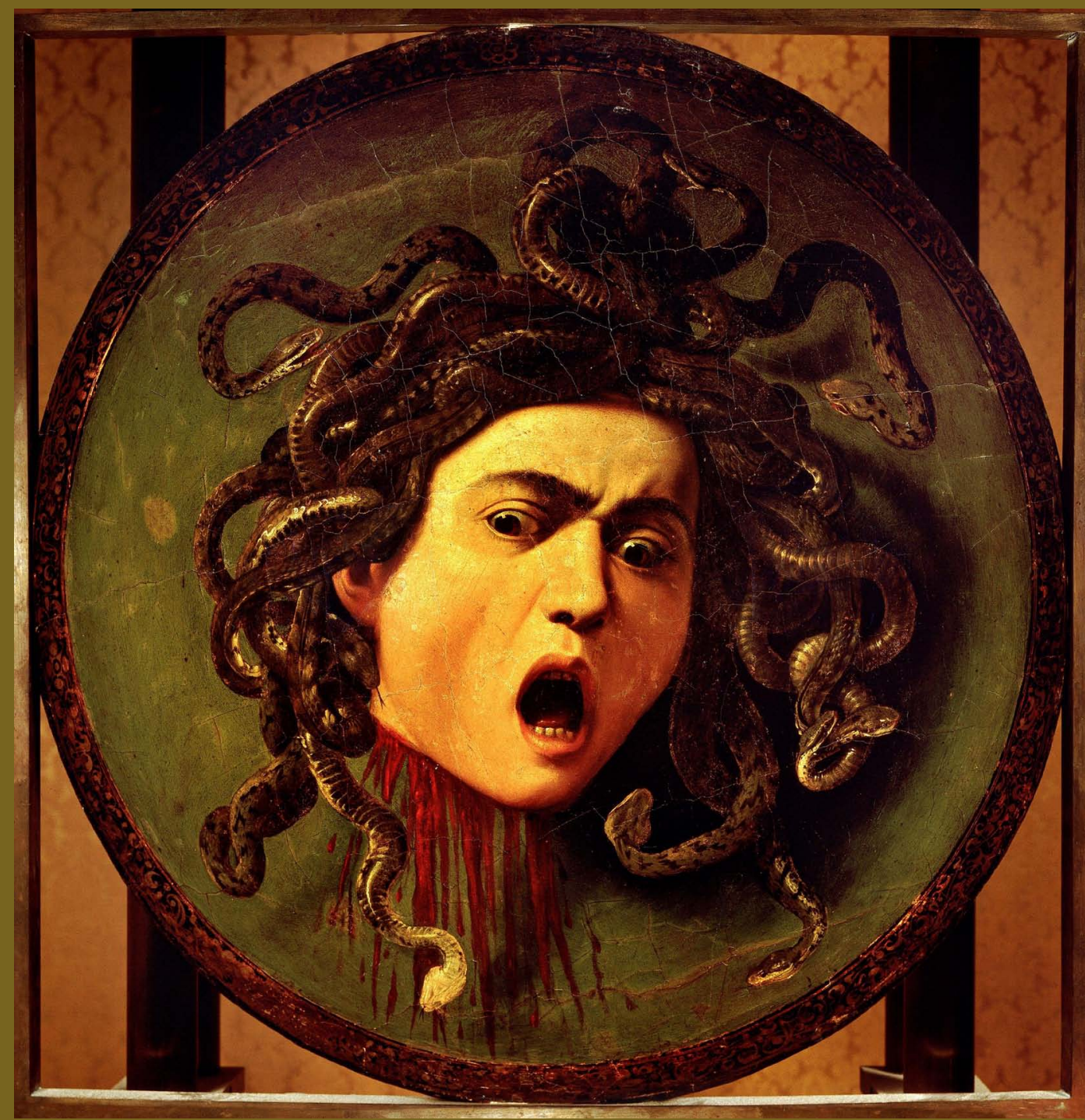

\section{R E V I S T A}
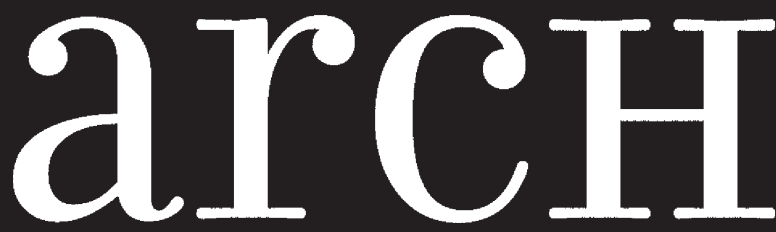
AS ORIGENS DO PENSAMENTO OCIDENTAL

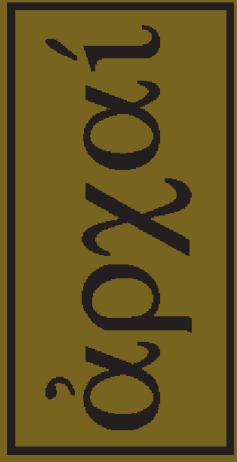

ARCHAI JOURNAL: ON THE ORIGINS OF WESTERN THOUGHT
arcHaI

arementam

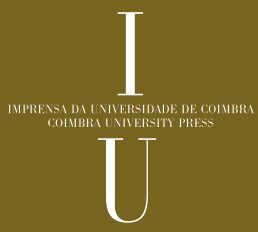

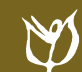

NNN 


\section{Lucas Soares. Enseñar filosofia o filosofía del enseñar: acerca de Platón y la política. Buenos Aires, Tecnos, 2010.}

BIEDA, E. (2012). “Lucas Soares. Enseñar filosofía o filosofía del enseñar: acerca de Platón y la política". Buenos Aires, Tecnos, 2010. Archai n. 9, jul-dez 2012, pp. 153-156.
* Universidad de Buenos Aires - CONICET

\section{Resenha de Esteban Bieda*}

Ante todo, acordemos un breve marco conceptual. En líneas generales, el objeto de estudio de la filosofía no son las cosas, sino las $I$ que los filósofos se hacen o tienen acerca de esas cosas. La etimología de la palabra "teoría" da cuenta de esto, dado que tiene que ver con la "contemplación" de algo, con la "visión" que se puede tener de un objeto, de un fenómeno o de una idea: una teoría no es la cosa sino una representación de la cosa. Siguiendo esta línea, la historia de la filosofía probablemente consista en una representación del modo en que tal o cual filósofo se ha representado, a su vez, determinada cosa: estaríamos ante una representación de representación. La distancia que media entre el historiador de la filosofía y el mundo podría parecer, así, casi insondable. Es por esta razón que algunos han afirmado que hacer historia de la filosofía no es una tarea filosófica sino, a lo sumo, historiográfica. En lo que sigue trataré de mostrar por qué, a mi juicio, el libro de Lucas Soares, Platón y la política, es una prueba que refuta dicha posición: no es sólo un libro de historia de la filosofía sino fundamentalmente un libro filosófico.

Comencemos por la expresión "hacer filosofía" o, mejor dicho, "tener a la filosofía como profesión en el siglo XXI". La posición más tradicional sugiere que hacer filosofía consiste en la creación de 
sistemas de conceptos capaces de dar cuenta del mundo circundante. Junto a este sentido clásico y restringido hay otro quizá demasiado amplio: si es cierto, como decíamos antes, que el filósofo no trabaja con el mundo sino con las representaciones que tiene acerca del mundo, alguien podría concluir que, en ese caso, cada hombre particular es un filósofo particular, alegando que las representaciones son particulares e intransferibles. Si la primera definición de "hacer filosofía" -en tanto creación de sistemas conceptuales- era demasiado estrecha, esta segunda parece demasiado amplia. ¿Qué estadios intermedios hay $v . g$. entre la intrincada prosa hegeliana y el taxista que se pregunta por las razones de su tristeza? ¿Qué puentes hay entre el plano de la teoría y el de la praxis en lo que respecta a las preguntas filosóficas por antonomasia: “¿qué es el mundo?", “¿qué es el hombre?"? Vayamos a esto.

En un tratado dedicado al estudio del alma Aristóteles insiste en que "filósofo" no es quien tan sólo posee conocimientos filosóficos, sino quien se sirve de ellos, quien los teoriza, quien los pone en acción. El hombre que posee conocimientos pero está dormido o no los utiliza no es filósofo en sentido pleno. El conocimiento por el conocimiento mismo no es una meta aristotélica. Ahora bien, ¿qué hay que entender por 'utilizar los conocimientos filosóficos'? Cuando Aristóteles se propone definir lo que entiende por "conocimiento" (epistéme), cosa que hace en el primer capítulo de la que probablemente sea su obra más compleja, la Metafísica, señala como característica fundamental su enseñabilidad. Es en ese contexto que sienta la siguiente posición: “signo para distinguir al que sabe del que no sabe es su capacidad de enseñar" (Met. 981b7). Alguien "sabio" no es, pues, quien simplemente posee conocimientos, sino quien es capaz de utilizarlos o actualizarlos, entre otros modos posibles, mediante la enseñanza. Enseñar filosofía es, sin dudas, uno de los puentes que buscábamos, uno de los lazos capaces de unir el mundo de las más abstractas teorías filosóficas y las quizá poco revisadas convicciones de quienes se acercan a la filosofía por primera vez. Un filósofo no es únicamente quien crea sistemas conceptuales complejos sino también quien los comparte pedagógicamente con sus alumnos.
¿Qué tiene que ver todo esto con el libro de Lucas Soares? Pues bien, en él se plasman esos dos aspectos que, sólo cuando unidos, hacen a la verdadera filosofía: la erudición teórica, por un lado, y el carácter irrenunciablemente didáctico con el que se la presenta, por el otro. Al conocimiento profundo y exhaustivo de las diversas representaciones que tuvo Platón acerca de su mundo $y$, en particular, de su realidad política, Lucas le suma la traducción a un plano donde se vuelve comunicable. Su libro no reposa, inerte, en el limbo de los análisis enrevesados e incomprensibles, sino que se compromete con la transmisión de la letra platónica sin por ello desatender la claridad y accesibilidad para el lector. Aun cuando es un fino estudioso de los complejos problemas de la filosofía antigua (y contemporánea), Lucas logra lo que pocos: hacerlo atractivo para cualquiera, dócil a la lectura para quien esté dispuesto a conocer cómo pensó Platón su entorno político y en qué dirección hubiese querido transformarlo. ¿Significa esto que estamos ante un manual de filosofía política platónica? De ningún modo, porque el libro no se limita a describir - pretensión del manual- sino que interpreta mediante una hipótesis rectora que lo recorre: "nuestra intención es desmitificar tanto la supuesta confianza ciega en la pintura ideal de gobierno que Platón delinea en República, como el presunto realismo extremo de Leyes. Como se intentará demostrar a lo largo del libro, el pensamiento platónico es un tanto más complejo..." (p.10). No se resume el pensamiento político platónico, sino que se lo interpreta sobre la base de un profundo respeto, tanto por la letra platónica como por los lectores. ¿Y qué es la docencia sino la re-presentación de ciertos contenidos conceptuales, sensatamente dosificados con las propias interpretaciones? Enseñar interpretando, lo que podríamos denominar una "didáctica hermenéutica", es una de las formas de la filosofía, y es lo que este libro propone.

Hay una idea que me interpela hace ya varios años: si hoy Platón viviera, no entendería la mayor parte de los libros que se escriben acerca de él. Y esto ocurriría, creo, porque hay 
quienes identifican "hacer filosofía" con "complicar lo sencillo". Tantos papers, libros monográficos, colecciones de artículos, todos escritos por los así (auto)denominados "mayores especialistas en la obra platónica", se definen, en algunos casos (porque por suerte hay varias excepciones), por su capacidad para complicar: cuánto más se enroscan los argumentos, más 'serio' y 'valioso' es el libro. ¿Desde cuándo la seriedad es eso? ¿Por qué no volver a los filósofos griegos del modo que proponía Pascal, pensador al que nadie se atrevería a negarle seriedad: "ordinariamente suele imaginarse a Platón y a Aristóteles con grandes togas y como personajes graves y serios; eran buenos sujetos, que se divertían, como los demás, en el seno de la amistad. Escribieron sus leyes y retratos de política para distraerse y divertirse: esa era la parte menos filosófica de su vida. La más filosófica era vivir sencilla y tranquilamente" (Pensamientos)? Montaigne se lamentaba de un modo similar: "borran de la historia que el más sabio y el más virtuoso de los hombres, Sócrates, bailaba" (Ensayos).

Desde mi punto de vista, un libro de filosofía no nace cuando es publicado; tampoco cuando es comprado por alguien. Un libro de filosofía nace cuando es leído. Pues bien, me atrevo a decir que todos esos libros "eruditos" o de "especialistas" no deben tener, a nivel mundial, más de mil o dos mil lectores, lectores entre los cuales, si estuviera vivo, probablemente no se contaría Platón. ¿Por qué no? Porque, como afirma Lucas en su libro a propósito del proyecto político platónico, "el hecho de erigir su primer y mejor orden político como un ideal inalcanzable en los mismos términos que supone el modelo (parádeigma), no significa que la pólis platónica se limite a una mera abstracción teórica, inviable en la práctica y sustraída al devenir histórico, sino que se trata más bien de un horizonte regulativo que apunta fundamentalmente a señalar un nuevo camino y la meta que debería proseguir de allí en más la verdadera política" (pp.232-3). El genio de Platón no consiste en lo que algunos consideran su 'idealismo': el creador de la teoría de las ideas no fue un idealista, al menos no en el sentido que hoy le damos al término. El genio de Platón consiste en su esfuerzo -quizás nunca definitivamente exitoso- por tratar de comunicar el plano de lo modélica y anheladamente perfecto con el de lo difuso y corruptible. A eso se refiere Lucas cuando afirma que "Platón nunca emprende su investigación acerca de lo político en abstracto, sino que pone en práctica un abordaje de naturaleza dual, el cual supone un ojo puesto en el análisis histórico [...] y otro puesto en la elaboración de una alternativa política de cuño personal" (p.229). Parafraseando este pasaje, me atrevo a decir que ‘Lucas nunca emprende su investigación, sea cual fuere, en abstracto, sino que pone en práctica un abordaje de naturaleza dual, el cual supone un ojo puesto en la transmisibilidad de los problemas a sus alumnos-lectores y otro puesto en la elaboración de una interpretación de cuño personal'. Muchos libros que estudian la filosofía antigua son escritos "en abstracto"; el de Lucas, por el contrario, se concreta en la misión cuasi divina de la enseñanza, de aquello que hace que cada hombre no sea una mónada cerrada sobre sí misma, sin posibilidad de comunicarse con sus pares. Lucas no escribió un libro para él mismo, no lo escribió para regodearse en un saber que, por ser incomprensible para muchos, sólo lo satisface a él y a unos pocos colegas; más bien escribió un libro que contiene la generosidad intelectual como marca distintiva. A propósito de la misión "cuasi divina" de la enseñanza, me refiero a que el verdadero docente es quien puede tener un ojo puesto en aquello que enseña y el otro en sus alumnos - paridad no siempre tenida en cuenta lo suficiente-. Este lugar 'intermedio' es lo que, según Platón, define nada menos que a Éros, semi-dios encargado de comunicar el plano divino con el humano. Es en ese sentido que hablamos de "eros docente": la docencia es una actividad erótica por cuanto supone un tipo de comunicación cimentada en dos deseos que se encuentran: deseo de saber, por un lado, y de enseñar, por el otro. Sin dudas, este libro contiene altas dosis de eros docente.

Ahora bien, ¿dónde se ve todo esto en el libro? En la mismísima "Introducción" encontramos el siguiente manifiesto: “se procuró equilibrar en el libro un tipo de exposición clara y ágil con el rigor filosófico y la pluralidad interpretativa que el tema amerita" (p.13). La claridad y la agilidad como 
contrapropuesta al lenguaje imbricado y ampuloso, pero sin resignar, por ello, rigor filosófico. Pero hay más: "se ha priorizado, tanto en el cuerpo central como en las notas, la utilización de fuentes primarias, las cuales apuntan a brindarle al lector mayores elementos de juicio a partir de apoyo textual" (p.13). Ya en la propuesta, Lucas le advierte al lector que no pretenderá persuadirlo de determinada línea interpretativa: el autor selecciona y presenta al lector su propia interpretación, pero también aquello que considera relevante para que el lector mismo pueda generar sus propias preguntas e interpretaciones. La filosofía está viva porque activa el pensamiento del lector que, si bien asiste a la exposición de teorías ajenas, no por eso es asfixiado con toneladas de bibliografía secundaria y de problemas tan rebuscados como alejados de la letra platónica. Si bien el libro cuenta con un gran número de notas al pie en las que el lector interesado o el especialista pueden encontrar referencias bibliográficas de toda índole para profundizar los problemas o conocer algunos debates de la crítica al respecto, no es eso lo más interesante que tiene. Porque sí: hay libros de historia de la filosofía que hacen que la filosofía se cierre sobre problemas que, paradójicamente, hacen que el pensamiento se detenga; algo similar a lo que le ocurrió al ciempiés de la madre de Gelman: "Siempre recuerdo una anécdota que me contó mi vieja, una leyenda rusa. Una vez estaba una arañita ahí al borde del camino y pasa un ciempiés. Entonces, la araña le dice: 'Señor ciempiés, qué complicado, ¿cómo hace para caminar? ¿Con los cincuenta pies izquierdos primero, cincuenta después de la derecha, diez y diez, uno y uno?'. Y el ciempiés se puso a pensar, y no caminó nunca más" (Juan Gelman, Revista Ñ 11/3/2006). El libro de Lucas invita a pensar a Platón pero en marcha, caminando, es decir: leyendo a Platón mismo, y no desde la atalaya de debates anquilosados y estancos. En una entrevista, Fernando Savater afirmaba: “yo creo que uno de los problemas principales del estudio de la filosofía es lograr entender de qué va 0 , mejor, cogerle la gracia: como los chistes. No es tan fácil. Isaiah Berlin empezó su vida académica como filósofo (era uno de los discípulos predilectos de Wittgenstein) pero luego dejó este primer amor para dedicarse a la historia de las ideas; cuando se le preguntó por las razones de tal cambio, repuso: 'Es que quiero estudiar algo de lo que al final pueda saber más que al principio (Diario El País, 02/09/2008). Cuando uno termina de leer el libro de Lucas puede tener la certeza de que sabe algo más que antes de leerlo.

En por todo esto que estoy convencido de que, si Platón viviera, sin dudas leería Platón y la política, entendería Platón y la política y, más importante aún, lo recomendaría a sus alumnos de la Academia. 